\title{
Research on Decoupled Optimal Control of Straight-Line Driving Stability of Electric Vehicles Driven by Four-Wheel Hub Motors
}

\author{
Songlin Yang ${ }^{1}$, Jingan Feng ${ }^{1, *}$ and Bao Song ${ }^{2}$ \\ 1 School of Mechanical and Electrical Engineering, Shihezi University, Shihezi 832000, China; \\ yangsonglin@stu.shzu.edu.cn \\ 2 School of Mechanical Science and Engineering, Huazhong University of Science and Technology, \\ Wuhan 430074, China; songbao@hust.edu.cn \\ * Correspondence: fia_mac@shzu.edu.cn; Tel.: +86-188-9959-7331
}

Citation: Yang, S.; Feng, J.; Song, B. Research on Decoupled Optimal Control of Straight-Line Driving Stability of Electric Vehicles Driven by Four-Wheel Hub Motors. Energies 2021, 14, 5766. https://doi.org/ $10.3390 /$ en14185766

Academic Editor:

Sheldon Williamson

Received: 16 August 2021

Accepted: 3 September 2021

Published: 13 September 2021

Publisher's Note: MDPI stays neutral with regard to jurisdictional claims in published maps and institutional affiliations.

Copyright: (C) 2021 by the authors. Licensee MDPI, Basel, Switzerland. This article is an open access article distributed under the terms and conditions of the Creative Commons Attribution (CC BY) license (https:// creativecommons.org/licenses/by/ $4.0 /)$.

\begin{abstract}
The optimal control strategy for the decoupling of drive torque is proposed for the problems of runaway and driving stability in straight-line driving of electric vehicles driven by four-wheel hub motors. The strategy uses a hierarchical control logic, with the upper control logic layer being responsible for additional transverse moment calculation and driving anti-slip control; the middle control logic layer is responsible for the spatial motion decoupling for the underlying coordinated distribution of the four-wheel drive torque, on the basis of which the drive anti-skid control of a wheel motor-driven electric vehicle that takes into account the transverse motion of the whole vehicle is realized; the lower control logic layer is responsible for the optimal distribution of the driving torque of the vehicle speed following control. Based on the vehicle dynamics software Carsim2019.0 and MATLAB/Simulink, a simulation model of a four-wheel hub motor-driven electric vehicle control system was built and simulated under typical operating conditions such as high coefficient of adhesion, low coefficient of adhesion and opposing road surfaces. The research shows that the wheel motor drive has the ability to control the stability of the whole vehicle with large intensity that the conventional half-axle drive does not have. Using the proposed joint decoupling control of the transverse pendulum motion and slip rate as well as the optimal distribution of the drive force with speed following, the transverse pendulum angular speed and slip rate can be effectively controlled with the premise of ensuring the vehicle speed, thus greatly improving the straight-line driving stability of the vehicle.
\end{abstract}

Keywords: hub motor; electric vehicles; straight-line driving stability; movement decoupling; optimal control

\section{Introduction}

Distributed drive is a new drive mode for electric vehicles in which the speed and torque of each drive wheel can be controlled quickly, accurately, and independently. It is even possible to drive on one side and brake on the other, facilitating drive/brake antiskid, power steering and active transverse moment control, thereby greatly improving the handling stability of the vehicle [1-3]. Based on these advantages, distributed drives have become a hot research topic in the field of electric vehicles. Distributed drives include both wheel-side drives and hub motor drives. In the last decade, hub motor-driven electric vehicles have been widely developed. The ground driving force of an electric vehicle driven by a hub motor acts directly on the body. As each wheel is independently driven, the force produced by each wheel on the body is different, which can effectively change the yaw of the body. Hub motor drive electric vehicle without a deceleration device, the wheel speed and motor the same, can directly control the motor and change the wheel speed [4].

GM, Ford, Mercedes Benz, and other automobile enterprises have applied hub motor technology in some of their electric vehicle models. GM applied the self-developed hub 
motor to the Chevrolet S-10 pickup truck. The wheel weight increased by only $15 \mathrm{~kg}$, but the driving torque was $60 \%$ higher than that of the ordinary Chevrolet S-10 fourcylinder pickup truck [5]. In [6-8], the hub motor drive adopts the direct torque control (DTC) control strategy. DTC is famous for its fast torque response, simple structure, and low parameter dependence [6]. However, it has the disadvantages of poor low-speed performance and large torque ripple [8]. In [9], a controller based on GWO algorithm is designed for all variables, which can minimize the speed ripple during low-speed and high-speed torque operation. It runs the optimization algorithm in real time to explore the optimal control input to ensure satisfactory dynamics.

Satoshi et al. carried out the force analysis of the additional torque of the whole vehicle generated by the transmission of the driving/braking torque of the hub motor through the suspension, as shown in Figure 1, which reflects that the hub motor drive has a stronger vehicle motion control effect than the half axle drive but did not reveal the essential mechanism and subsequent control method of the additional torque generated by the hub motor drive [10]. In [11], through mechanical analysis, it is concluded that the reaction torque of wheel driving torque of wheel motor-driven vehicle on suspension is much greater than that of traditional half axle driven vehicle, which is directly transmitted back to the transmission system through the half axle and acts on the body position fixed by the transmission system. Finally, the yaw stability controller based on model predictive control and the roll stability controller based on feedback optimal control are designed. The bottom coordinated distribution of four-wheel drive torque is carried out through spatial motion decoupling, and the roll stability control of hub motor-driven electric vehicle considering the yaw motion of the whole vehicle is realized.

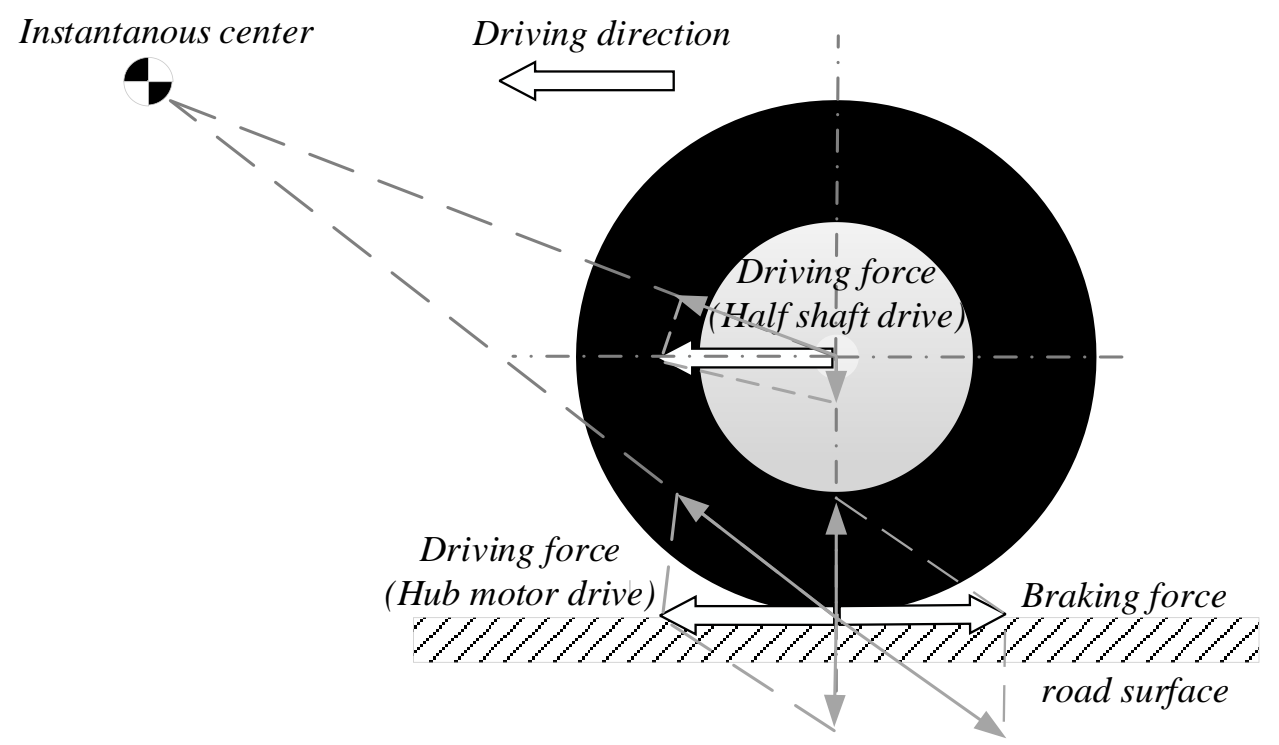

Figure 1. Hub motor drive versus half shaft drive.

Zheng Yuanbai et al. installed the hub motor on both sides of the semi-trailer and generated the differential torque by coordinating and controlling the driving/braking torque of the hub motor and the differential braking of the mechanical braking system, so as to effectively improve the lateral stability of the vehicle. The research shows that this strategy is better than the traditional differential braking control system (ESP) [12]. Ma Haiying et al. studied the influence of different wind angles, crosswinds, and vehicle speeds on the straight-line driving of electric vehicles driven by four-wheel hub motors, and established a direct yaw moment control model based on fuzzy logic to improve the straight-line driving stability of electric vehicles driven by four-wheel in-wheel motors under crosswinds. The results proves that velocity of vehicle make biggest difference to the 
influence on vehicle under the cross wind, and the DYC model can decline the amplitude of yaw rate and improve the straight-line stability of vehicle well [13].

Due to the changes in the structure and drive system of a hub motor-driven electric vehicle and the changes in the vehicle's handling stability, passability, dynamics, and smoothness, it is particularly important to establish control technology suitable for distributed drive vehicles with reference to conventional vehicle control systems. Among them, the vehicle straight-line driving performance as the primary solution, can reduce the difficulty of the driver to maneuver the vehicle, improve the safety, power and passability of the vehicle in high-speed straight-line driving, can increase the driver's ability to deal with complex road conditions, is the four-wheel hub motor drive vehicles focus on solving the technology.

Straight-line driving stability includes the lateral stability of the vehicle, the rate of wheel slip, and the response of the vehicle speed. Conventional transverse stability strategies for Distributed Drive Electric Vehicles (DDEV) are usually implemented by means of a torque distribution strategy [14-16]. To ensure the robustness of the vehicle system, the conventional control algorithm is usually optimized [17-19]. For example, Eman Mousavinejad has developed an integrated vehicle dynamics control algorithm that improves the transient response of vehicle yaw rate and side slip angle tracking controllers using both integral and non-singular fast terminal sliding mode (NFTSM) control strategies [20]. Carrie G. Bobier-Tiu and Craig E. Beal extend the application of phase diagrams in vehicle dynamics to control synthesis by illustrating the relationship between the boundaries of stable vehicle operation and the state derivative contours of the yaw rate-slippage phase plane because of their high fidelity in capturing planar stability characteristics [21]. Some people designed a BP-PID controller based multi-model control system (MMCS) for DDEV by direct yaw control (DYC), which ensured the lateral stability of DDEV under different road adhesion coefficients [22].

As one of the most popular vehicle active safety systems, acceleration slip regulation (ASR) is widely used in distributed drive electric vehicles to improve vehicle acceleration performance $[23,24]$. Guodong Yin proposes an accelerated slip regulation (ASR) algorithm based on a fuzzy logic control strategy to keep the wheel slip rate within the optimum range by dynamically adjusting the motor torque [25]. A new robust adaptive algorithm based on a state observer is designed to achieve tracking control of wheel slip rates [26]. In view of the long braking time of the existing wheel slip rate control method, the obvious gap between the slip rate and the optimal slip rate, and the poor control effect, the fuzzy algorithm is introduced to design the wheel slip control method to improve the control effect [27].

Distributed-drive electric vehicles use four hub motors to drive four wheels, each of which can be controlled independently. It is particularly important that each wheel speed is coordinated during the drive, which ensures the stability of the vehicle as it accelerates to the desired speed. A robust control method is used to control the permanent magnet synchronous motor, controlling and maintaining the vehicle speed and motor torque within the driver's desired reference range [28].

To ensure the stability of distributed drive electric vehicles in a straight line, three conditions have to be fulfilled:

(1) Yaw stability

(2) The slip rate is in a safe area

(3) speed follows desired speed

Regardless of whether it is a traditional car or an in-wheel motor-driven electric car, most of the research studies on the control of motion stability use a single variable to optimize the control algorithm. Although it brings performance improvements in this area, it still affects other variables. As a multi-variable coupling system, the vehicle system's lateral movement, slip rate, and speed are all regulated by the driving torque, which makes the distribution of the driving wheel torque very difficult. Therefore, the control process 
must consider the problem of kinematic coupling to achieve the optimal distribution of wheel drive torque to ensure that each variable can reach the optimal state.

For this reason, this paper selects the yaw rate, slip rate, and vehicle speed as the control variables, and designs the four-wheel hub motor-driven electric vehicle straightdriving stability decoupling optimal control system to ensure the stability of the vehicle in the straight-line driving process. It is an innovation that strives to achieve a balance between the multiple variables of the vehicle system. Working conditions such as high and low adhesion coefficient roads and split roads have verified the effectiveness of the control system. The symbols and meanings involved in this formula are shown in Table 1.

Table 1. Nomenclature.

\begin{tabular}{cc}
\hline Symbol & Physical Meaning \\
\hline$F_{x i j}$ & Longitudinal driving force \\
$F_{y i j}$ & Lateral driving force \\
$F_{z i j}$ & Vertical force \\
$\omega_{r}$ & Yaw rate \\
$\alpha_{i j}$ & Slip angle \\
$v_{x}$ & Longitudinal speed \\
$S_{i j}$ & Slip rate \\
$w_{i j}$ & Wheel speed \\
$T_{i j}$ & Driving torque \\
$k_{f}$ & Front axle vertical load proportion \\
$k_{r}$ & Rear axle vertical load specific gravity \\
$i j$ & Front left $(f l)$, front right $(f r)$, rear left $(r l)$, rear right $(r r)$ \\
\hline
\end{tabular}

\section{Vehicle Stability Analysis in a Straight Line}

As shown in Figure 2, the vehicle is running in a straight line with the front wheels turning at an angle of 0 . When the driving forces of the wheels on both sides of the vehicle are not balanced, assuming $F_{x r l}+F_{x r r}>F_{x f l}+F_{x r l}$, the longitudinal driving force of the wheels on both sides will produce a counterclockwise torque around the center of mass axis. To achieve a state of kinematic equilibrium, the tire is sideways deflected and the lateral force on the front axle of the wheel will generate a clockwise moment around the center of mass axis to counteract the increase in angular velocity of the transverse pendulum. With the increase of tire lateral force, the torque generated by longitudinal and lateral forces of the wheel around the centroid axis is balanced. This process will produce a non-zero yaw rate and lateral velocity, causing the vehicle to continue to run off track.

In addition, when the vehicle is running on a low-adhesion road, the wheel driving torque can easily exceed the maximum torque provided by the road, causing excessive wheel slip, and the vehicle's ability to resist lateral interference is weakened, even if it is subjected to a small lateral force. The wheels will also slip, making the vehicle unable to drive stably, and aggravate the deviation of the vehicle.

Therefore, the reason for the deviation of the vehicle in a straight line is the imbalance of the driving force of the wheels on both sides of the vehicle, which causes the vehicle to produce yaw rate, which causes the vehicle to yaw and deviate from the predetermined trajectory. Especially when the wheels are excessively slipped, the vehicle will slip. With a loss of stability, the amount of deviation will further increase. 


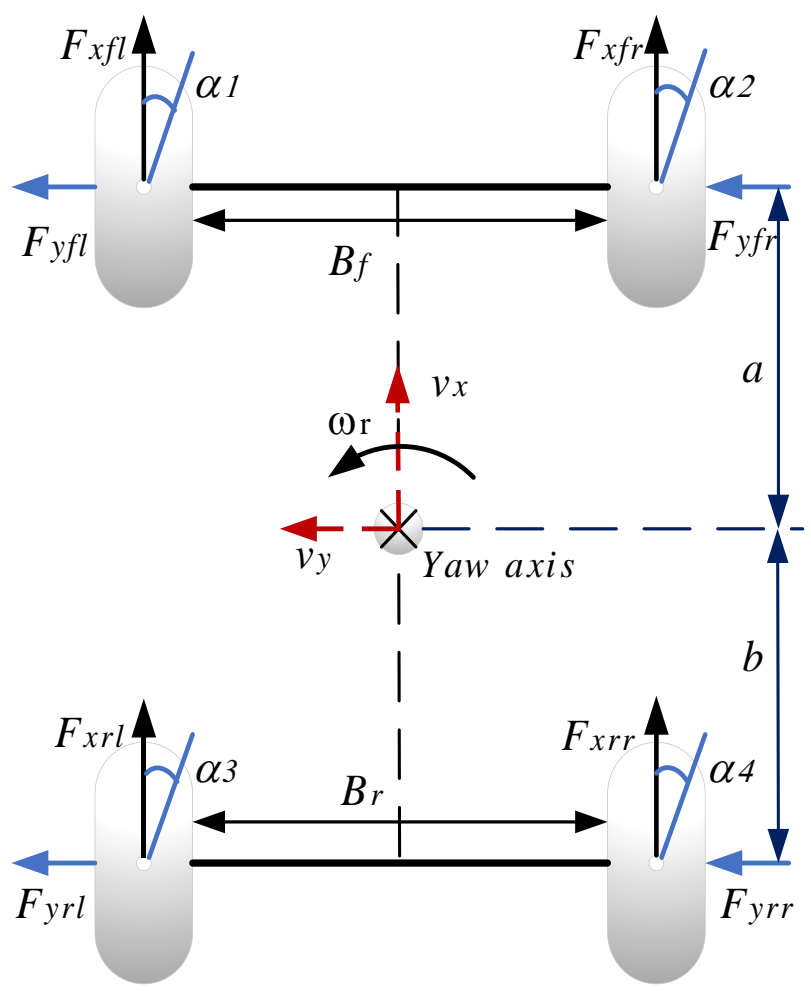

Figure 2. Vehicle straight-line driving dynamics model.

\section{Vehicle Modelling and Experimental Verification}

\subsection{Vehicle Model}

Complete vehicle dynamics modelling with Carsim2019.0. The object of study in this paper is a hub motor-driven electric vehicle, whose transmission structure does not include transmission components such as engine, gearbox and differential. As shown in Figure 3, when building the distributed drive system, the torque source for each wheel was disconnected from the conventional powertrain and all external interface inputs were used in order to be able to control the drive/brake torque of the four-wheel motors in real time. The drivetrain (hub motor model) for this paper was built in the software MATLAB/Simulink, and the vehicle dynamics model was refined through a communication interface in both software.

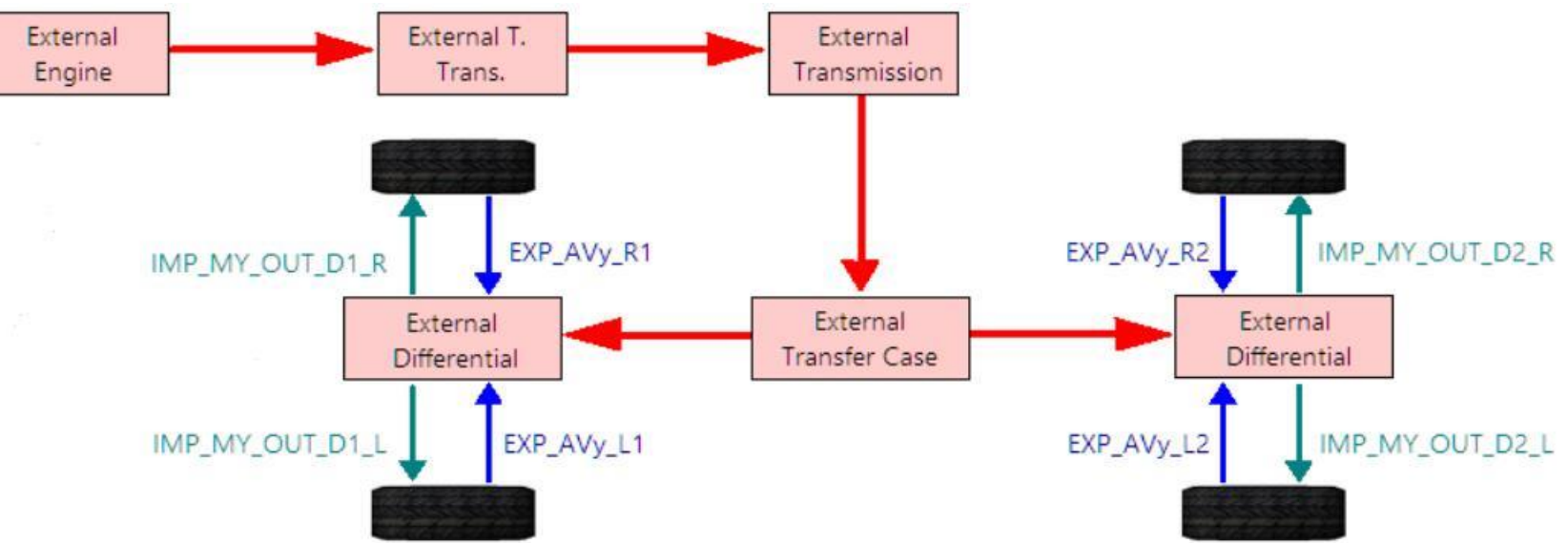

Figure 3. Drive system. 


\subsection{Wheel Hub Motor Matching Calculation}

In this paper, the simulated outer rotor permanent magnet synchronous motor is used as the hub motor of the vehicle. According to the vehicle parameters in Table 2, the vehicle power transmission system matching design is carried out. The demand power formula of the vehicle in any kind of driving condition is as follows [29]:

$$
P_{t}=\left(M g f \cos i+M g \sin i+\frac{C_{D} A}{21.15} u^{2}+\delta M \frac{d u}{3.6 d t}\right) \frac{u}{3600 \eta}
$$

Table 2. Vehicle parameters.

\begin{tabular}{cccc}
\hline Parameter & Value & Unit & Physical Meaning \\
\hline$M$ & 1200 & $\mathrm{~kg}$ & Total mass of vehicle \\
$g$ & 9.8 & $\mathrm{~m} / \mathrm{s}^{2}$ & Gravitational acceleration \\
$I_{z}$ & 1343.1 & $\mathrm{~kg} \cdot \mathrm{m}^{2}$ & Yaw inertia \\
$a$ & 1.04 & $\mathrm{~m}$ & Distance from front axle to COG \\
$b$ & 1.56 & $\mathrm{~m}$ & Distance from rear axle to COG \\
$B_{f}$ & 0.775 & $\mathrm{~m}$ & Half length of front axle \\
$B_{r}$ & 0.775 & $\mathrm{~m}$ & Half length of rear axle \\
$r$ & 0.308 & $\mathrm{~m}$ & Wheel radius \\
\hline
\end{tabular}

In the formula, $P_{t}$ is the required power for driving of the vehicle; $M$ is the curb weight of the vehicle; $f$ is the rolling resistance coefficient of the vehicle; $g$ is the acceleration of gravity; $C_{D}$ is the air resistance coefficient; $A$ is the windward area of the vehicle; $u$ is the speed of the vehicle; $\delta$ is the conversion factor of rotational inertia; $\eta$ is the mechanical transmission efficiency; $i$ is the road gradient.

By setting the parameters, $f=0.01, C_{D}=0.32, A=1 \mathrm{~m}^{2}, \eta=0.9$. To make the powertrain meet the conditions:

$$
u_{\text {max }} \geq 120 \mathrm{~km} / \mathrm{h}
$$

Calculated from Equation (1):

$$
P \geq 3 \mathrm{kw}
$$

At the same time the powertrain needs to meet the vehicle's maximum climbing requirements, when the vehicle is climbing at speed $u \geq 30 \mathrm{~km} / \mathrm{h}$ on a road with a gradient angle $i \geq 30^{\circ}$.

Calculated from Equation (1):

$$
P \geq 12 \mathrm{kw}
$$

In addition, the maximum speed of the hub motor needs to meet the maximum speed target of the vehicle.

$$
n_{\max } \geq \frac{1000 u_{\max }}{120 \pi r}
$$

where $u$ is the vehicle speed, $u_{\max }$ is the maximum vehicle speed, $P$ is the wheel hub motor demand power, and $n_{\max }$ is the maximum wheel hub motor speed.

Based on the above calculations, a hub motor was selected with the parameters shown in Table 3.

$$
T=\left(\begin{array}{ll}
T_{w} & 0<n<n_{e} \\
9550 \cdot P_{w} / n & n_{e} \leq n \leq n_{w}
\end{array}\right.
$$


Table 3. Wheel motor parameters.

\begin{tabular}{cccc}
\hline Parameter & Value & Unit & Physical Meaning \\
\hline$P_{e}$ & 14 & $\mathrm{kw}$ & Power rating \\
\hline$P_{t}$ & 28 & $\mathrm{kw}$ & Peak power \\
\hline$n_{e}$ & 800 & $\mathrm{rpm}$ & Rated speed \\
\hline$n_{w}$ & 1600 & $\mathrm{rpm}$ & Peak speed \\
\hline$T_{e}$ & 145 & $\mathrm{~N} \cdot \mathrm{m}$ & Rated torque \\
\hline$T_{w}$ & 290 & $\mathrm{~N} \cdot \mathrm{m}$ & Peak torque \\
\hline
\end{tabular}

Pure mathematical approach to hub motor modelling: the maximum drive torque of the wheel hub motor can be calculated using the S-function in MATLAB and compared with the torque calculated for each drive wheel by the control strategy. When the maximum drive torque of the hub motor is large, the calculated drive wheel torque is output; when the maximum drive torque of the hub motor is small, the maximum drive torque is output.

\section{CarSim Vehicle Model Straight-Line Driving Capability Validation}

The vehicle power system establishes a vehicle longitudinal speed following module based on a PID controller, based on the driver's desired speed expectation, the longitudinal drive force is calculated in real time and distributed equally among the four drive motors (this drive method is referred to as the no controlled model in the simulation).

After completing the vehicle dynamics model based on CarSim2019.0 software, the vehicle's ability to drive in a straight line needs to be verified to ensure the accuracy of the vehicle modelling.

The vehicle model was validated under simulated road conditions with a road adhesion coefficient of 1.0. In Figures 4-6, the simulation results show that during the acceleration of the vehicle from $0 \mathrm{~km} / \mathrm{h}$ to $72 \mathrm{~km} / \mathrm{h}$, the lateral displacement and Yaw rate are both of order of magnitude below $1 \times 10^{-2}$.

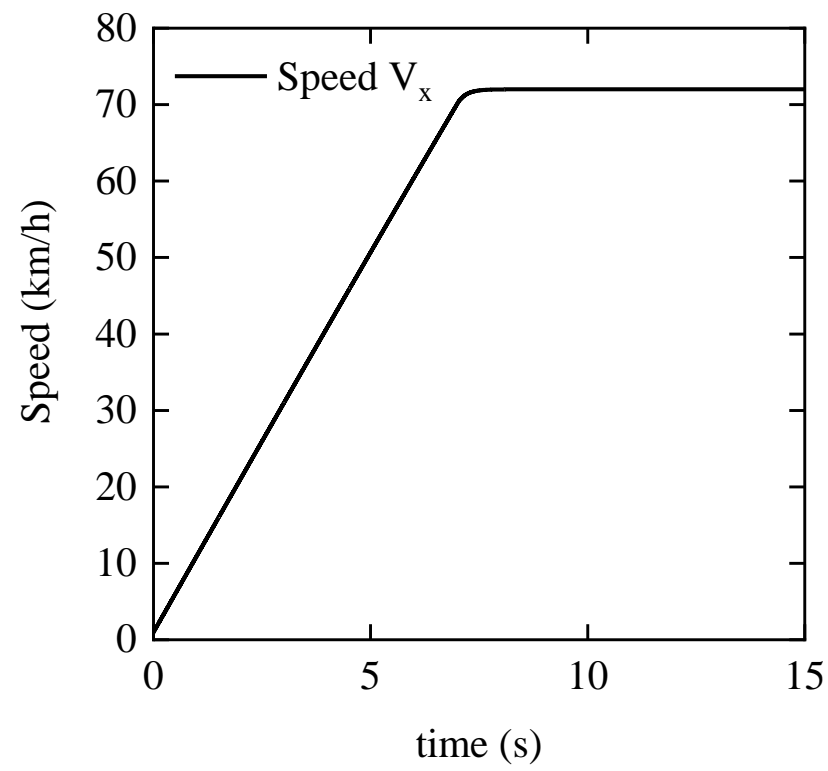

Figure 4. Longitudinal speed. 


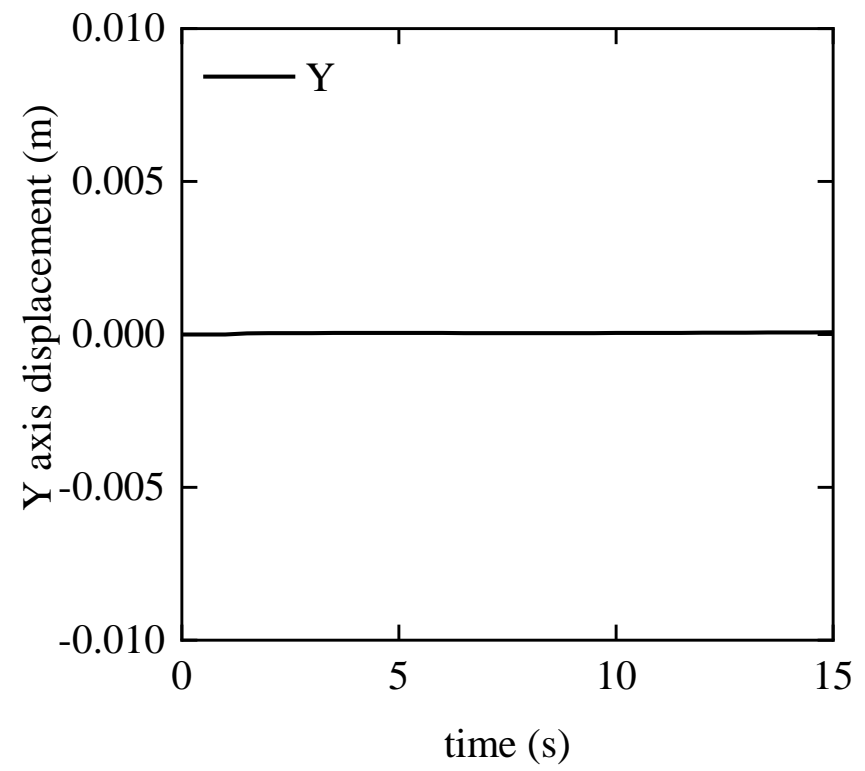

Figure 5. Displacement in the $Y$-axis direction.

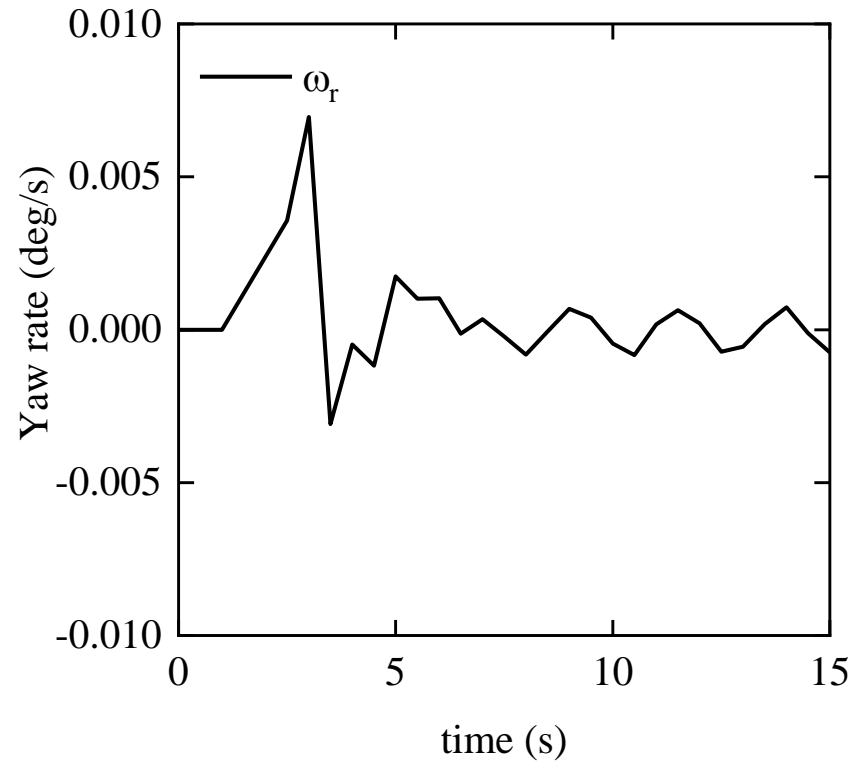

Figure 6. Yaw rate.

As a result, the vehicle has good straight-line performance and can be used to verify the validity of the algorithm.

\section{Decoupled Optimal Control of Straight-Line Driving Stability}

Control System Architecture Design

Yaw rate is one of the best state variables to describe the stability of a vehicle's chassis motion, and wheel slip rate refers to the ratio of the difference between the theoretical and actual speed of the vehicle to the theoretical speed. The slip ratio affects both average speed and energy consumption.

In this paper, Yaw rate is taken as the control variable of the transverse pendulum motion and the wheel speed is taken as the control variable of the slip rate, and the joint decoupling control of Yaw rate and slip rate is carried out, and finally the drive force based on the speed following control is optimally distributed. 
First, the desired yaw rate is determined; the desired yaw torque increment is calculated in real time by the yaw motion model prediction controller; First, the desired yaw rate $\omega_{d}$ is determined; the desired yaw torque increment $\Delta M z$ is calculated in real time by the yaw motion model prediction controller; then, the corresponding expected wheel speed 1 through the optimal slip rate $w_{\text {ref }}$ of the current road surface is obtained, the gain torque $\Delta T_{i j}$ of each wheel is obtained by PID control method; Then, the yaw torque increment and the wheel drive anti-skid gain torque are jointly controlled and decoupled to obtain the torque increments $\Delta T_{f l}, \Delta T_{f r}, \Delta T_{r l}, \Delta T_{r r}$ of the four driving wheels; Finally, the generalized drive force of the whole vehicle is found by sliding mode control according to the desired vehicle speed, based on the quadratic programming algorithm of tire utilization rate, the generalized driving force is optimally allocated.

Thus, the final driving torques $T_{f l}+\Delta T_{f l}, T_{f r}+\Delta T_{f r}, T_{r l}+\Delta T_{r l}, T_{r r}+\Delta T_{r r}$ are obtained; to complete the closed loop control, they are input into the complete vehicle model. The whole control process is shown in Figure 7.

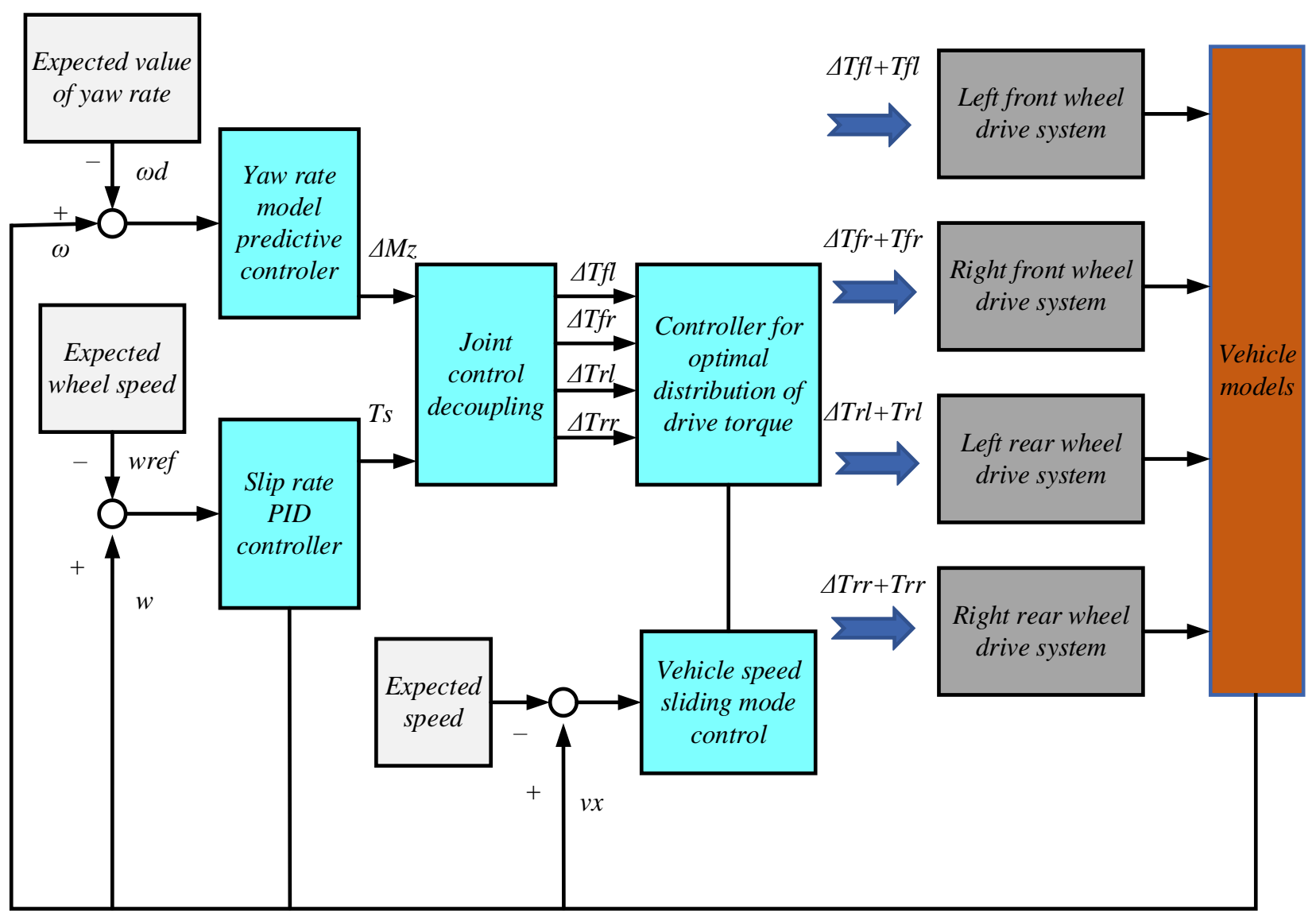

Figure 7. Decoupled optimal control system framework.

\section{Yaw Motion Controller Design}

\subsection{Expectation Model}

Assuming the vehicle is travelling in a straight line with no wheel slip, constant longitudinal speed, little lateral acceleration and tire lateral deflection characteristics in a linear range, the vehicle is in equilibrium after neglecting lateral, pitch, longitudinal and vertical movements.

The control of the yaw motion is controlled by the additional driving force and torque generated by the hub motor on the driving wheels. 
Yaw motion expectation equation:

$$
I_{z} \dot{\omega}_{r}=\Delta M_{z}
$$

Its equation of state:

$$
\dot{X}=A X+B U
$$

In the formula, $A=\left[\begin{array}{ll}0 & 1 \\ 0 & 0\end{array}\right], B=\left[\begin{array}{c}0 \\ \frac{1}{I_{z}}\end{array}\right]$.

\subsection{Design of the Model Predictive Controller}

The state Equation (8) is discretized using the forward Euler method.

$$
\begin{gathered}
\dot{X}=\frac{X(k+1)-X(k)}{T}=A X(k)+B U(k) \\
X(k+1)=(1+T A) X(k)+T B U(k) \\
X(k+1)=\bar{A} X(k)+\bar{B} U(k)
\end{gathered}
$$

Take the system state predicted in the next $\rho$ control cycle as follows:

$$
X_{k}=\left[\begin{array}{llll}
X(k+1 / k)^{T} & X(k+2 / k)^{T} \quad \ldots \quad X(k+\rho / k)^{T}
\end{array}\right]
$$

The control quantities in the predicted time domain are:

$$
U_{k}=\left[\begin{array}{llll}
U(k / k)^{T} & U(k+1 / k)^{T} \quad \ldots & U(k+\rho-1 / k)^{T}
\end{array}\right]
$$

Through the discretized state equation, the system state in the next $\rho$ control cycles is predicted in turn:

$$
\begin{gathered}
X_{k}=\Psi X(k)+\Theta U_{k} \\
\text { Among them, } \Psi=\left[\begin{array}{c}
\bar{A}^{1} \\
\bar{A}^{2} \\
\bar{A}^{\rho}
\end{array}\right], \Theta=\left[\begin{array}{cccc}
\bar{A}^{1-1} \bar{B} & \ldots & 0 & 0 \\
\bar{A}^{2-1} \bar{B} & \bar{A}^{2-2} \bar{B} & \ldots & 0 \\
\bar{A}^{3-1} \bar{B} & \bar{A}^{3-2} \bar{B} & \ddots & \bar{A}^{\rho-\rho} \bar{B} \\
\bar{A}^{\rho-1} \bar{B} & \bar{A}^{\rho-1} \bar{B} & \ldots & \text { define }
\end{array}\right.
\end{gathered}
$$

an optimization objective function in terms of the cumulative error between the predicted state vector and the reference value.

$$
\begin{aligned}
& J\left(U_{k}\right)=\left(X_{k}-R_{k}\right)^{T} Q\left(X_{k}-R_{k}\right)+U_{k}^{T} W U_{k} \\
& \text { s.t. }|U(k+i / k)| \leq T_{L}, i=0,1,2, \ldots, \rho-1
\end{aligned}
$$

In the formula, $T_{L}$ is the maximum remaining driving torque.

The quadprog function of the MATLAB toolbox can be used to solve the control input increment $U(k)$ at time $k$.

In the formula, $U(k)$ is $\Delta M z$. At this point, the yaw torque increment can be obtained.

\subsection{Design of Acceleration Slip Controller}

When the wheels are in excessive slip, the vehicle will slip sideways even when subjected to a small lateral force and thus lose stability. Therefore, when the wheel slip rate exceeds the optimal slip rate $S_{O P T}$, the wheel is considered to have excessive slip, and the wheel speed needs to be controlled by driving torque to make the wheel run within a stable range.

The slip rate equation is $[30,31]$ :

$$
S_{i j}=\frac{\omega_{i j} r-v}{\omega_{i j} r}
$$


when the wheel is at the optimum slip rate $S_{O P T}$, the wheel has the desired angular velocity $w_{\text {ref }}$, i.e., there is a correspondence between the desired angular velocity $w_{\text {ref }}$ and the optimum slip rate $S_{O P T}$.

$$
\omega_{\text {ref }}=\frac{v}{r\left(1-S_{O P T}\right)}
$$

Equations (16) and (17) show the input-output relationship between speed and slip rate, and pid control is simpler and more efficient in processing this relationship [32-35]. When the wheel slip rate exceeds the optimal slip rate, the actual wheel speed is greater than the expected wheel speed. At this time, the wheel slips excessively. The PI controller is used to control the wheel speed to obtain the adjusting torque $\Delta T_{s i j}$.

$$
\left\{\begin{array}{l}
e_{i j}=\omega_{r e f}-\omega_{i j} \\
\Delta T_{\mathrm{sij}}=k_{p} e_{i j}+k_{i} \int e_{i j} d(t)
\end{array}\right.
$$

when the wheel slip rate is less than the optimal slip rate, the actual wheel speed is less than the expected wheel speed, the wheel does not slip excessively, and it is in a normal state. The adjustment torque $\Delta T_{s i j}=0$.

\section{Decoupling of Underlying Control and Motion}

\subsection{Yaw Movement Bottom Control}

The resulting force analysis of the entire vehicle plane motion is shown in Figure 8. $\Delta F_{x f l}, \Delta F_{x f r}, \Delta F_{x r l}, \Delta F_{x r r}$ are the drive force increments of the four wheels and $\alpha_{1}, \alpha_{2}, \alpha_{3}$, $\alpha_{4}$ are the lateral deflection angles of the four wheels.

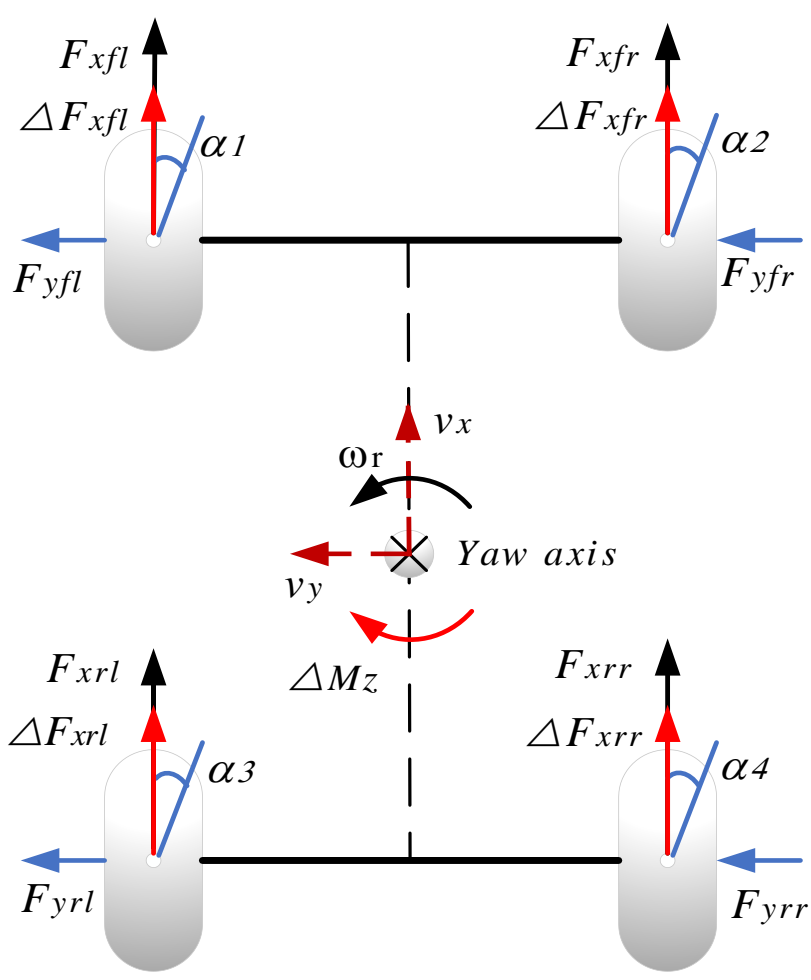

Figure 8. Linear motion diagram of the whole vehicle.

The additional yaw moment obtained is distributed by the vertical load proportion of the front and rear axles.

$$
\Delta M_{z}=k_{f} \frac{\Delta F_{x f r} B_{f}}{2}+k_{r} \frac{\Delta F_{x r r} B_{r}}{2}-k_{f} \frac{\Delta F_{x f l} B_{f}}{2}-k_{r} \frac{\Delta F_{x r l} B_{r}}{2}
$$




\subsection{Slip Rate Bottom Control}

The drive to each wheel is distributed according to the regulated torque of the individual wheels.

Drive force increment of left front wheel:

$$
\Delta F_{x f l}=\Delta T_{s f l} / r
$$

Drive force increment of right front wheel:

$$
\Delta F_{x f r}=\Delta T_{s f r} / r
$$

Drive force increment of left rear wheel:

$$
\Delta F_{x r l}=\Delta T_{s r l} / r
$$

Drive force increment of right rear wheel:

$$
\Delta F_{x r r}=\Delta T_{s r r} / r
$$

\subsection{Decoupling Control}

Since the control of yaw rate and slip rate is derived from the driving force and torque of the wheels, it is necessary to perform joint control and necessary control decoupling in the bottom distribution of torque.

The decoupling is done as follows.

Rewrite Equations (19)-(23) in matrix form as:

$$
v=B u
$$

Among them, $v=\left[\begin{array}{cc}\Delta M z & \Delta T\end{array}\right]^{T}, u=\left[\begin{array}{llll}\Delta F_{x f l} & \Delta F_{x f r} & \Delta F_{x r l} & \Delta F_{x r r}\end{array}\right]^{T}$, $B=\left[\begin{array}{cccc}-\frac{k_{f} B_{f}}{2} & \frac{k_{f} B_{f}}{2} & -\frac{k_{r} B_{r}}{2} & \frac{k_{r} B_{r}}{2} \\ r & r & r & r\end{array}\right]$.

The torque constraints of the hub motor need to be taken into account when actually distributing the motor torque.

$$
T_{d \max } / r \leq u_{i} \leq T_{l \max } / r
$$

where $T_{\text {dmax }}$ is the maximum residual braking torque and $T_{l \max }$ is the maximum residual driving torque, $i=1,2,3,4$.

Under the constraints of Formula (25), the formula may not have a solution. To ensure that the problem can be solved, the Formulas (24) and (25) are combined as:

$$
\Omega=\min _{u_{\min } \leq u \leq u_{\max }}\|W(B u-v)\|_{2}^{2}
$$

where $\Omega$ is the domain of feasible solutions and $W$ is the control weights such that, $W=\operatorname{diag}\left(\begin{array}{ll}w_{1} & w_{2}\end{array}\right)$, and $w_{1}, w_{2}$ are the weights controlling yaw rate and slip rate.

After obtaining the driving force increments $\Delta F_{x f l}, \Delta F_{x f r}, \Delta F_{x r l}, \Delta F_{x r r}$ of each driving wheel, the driving torque increments of each driving wheel $\Delta T_{f l}, \Delta T_{f r}, \Delta T_{r l}, \Delta T_{r r}$ can be obtained by Formula (27):

$$
\left\{\begin{aligned}
\Delta T_{f l} & =\Delta F_{x f l} \cdot r \\
\Delta T_{f r} & =\Delta F_{x f r} \cdot r \\
\Delta T_{r l} & =\Delta F_{x r l} \cdot r \\
\Delta T_{r r} & =\Delta F_{x r r} \cdot r
\end{aligned}\right.
$$

In this way, the final drive torque increment assigned to each wheel is obtained and input into the vehicle model. 


\section{Optimal Distribution of the Generalized Drive Torque}

Vehicle longitudinal speed Equation [36]:

$$
M\left(\dot{v}+q \omega-\omega_{r} u\right)=M_{s} h^{\prime}\left(\dot{q}+p \omega_{r}\right)+F_{x}-M g \sin i-\frac{1}{2} C_{D} A_{f} \rho_{a} v^{2}
$$

In the formula, $v, u, \omega$ are the longitudinal, transverse and vertical velocities respectively, $\omega_{r}, p, q$ are the yaw rate, roll rate and pitch rate, respectively, $M_{S}$ is the sprung mass.

The vehicle speed is tracked using a sliding mode variable structure control method, using the vehicle longitudinal speed as the sliding mode function for error tracking.

$$
s_{v}=v_{x}-v_{x d}
$$

get:

$$
\begin{aligned}
& \dot{s}_{v}=\dot{v}_{x}-\dot{v}_{x d}=\frac{1}{M}\left(M_{s} h^{\prime}\left(\dot{q}+p \omega_{r}\right)+F_{x}-M g \sin i-\frac{1}{2} C_{D} A_{f} \rho_{a} v^{2}\right) \\
& -q \omega+w_{r} v-\dot{v}_{x d}
\end{aligned}
$$

Taking the exponential rate of convergence of the saturation function.

$$
\dot{s}_{v}=-\varepsilon s a t\left(s_{v}\right)-k_{v} s_{v} \quad \varepsilon>0, k_{v}>0
$$

The control equation is obtained as:

$$
F_{x}=M_{s} h^{\prime}(\dot{q}+p \gamma)+-M g \sin i-\frac{1}{2} C_{D} A_{f} \rho_{a} u^{2}+q \omega-\gamma v+\dot{v}_{x d}-\varepsilon s a t\left(s_{v}\right)-k_{v} s_{v}
$$

The generalized drive force for the whole vehicle drive $F_{x}$ is obtained from Equation (32) to achieve the tracking of the expected vehicle speed.

The longitudinal generalized force is equally distributed to the four driving wheels according to the previous principle of equal distribution, without considering factors such as vehicle axle load transfer, motor and braking system output torque limitations, and road adhesion conditions, which will reduce the robustness of the vehicle stability control system.

Therefore, the generalized driving force is optimally allocated, and the optimal value of the driving force of each wheel is solved by the quadratic programming algorithm based on the tire utilization rate [37].

$$
\rho_{i j}=\frac{F_{x i j}}{\mu_{i j} F_{z i j}}
$$

In Equation (33), $\rho_{i j}$ is the tire utilization rate and $\mu_{i j}$ is the road adhesion coefficient. The equation for the total longitudinal force on the vehicle is shown below.

$$
F_{x}=F_{x f l}+F_{x f r}+F_{x r l}+F_{x r r}
$$

Rewritten into matrix form:

$$
F_{x}=B u
$$

where, $B=\left[\begin{array}{llll}1 & 1 & 1 & 1\end{array}\right] ; u=\left[\begin{array}{llll}F_{x f l} & F_{x f r} & F_{x r l} & F_{x r r}\end{array}\right]^{T}$.

In mathematics, nonlinear programming is to solve an optimization problem defined by a set of equations and inequalities (collectively referred to as constraints) consisting of a series of unknown real functions, accompanied by an objective function to be maximized or minimized, just some constraints or the objective function is non-linear. It is the most common method for optimally handling nonlinear problems [38-46]. Taking the minimum square sum of all tire utilization rates as the objective function to distribute the force of each tire, it can ensure that each wheel can remain stable and have a certain stability margin 
to ensure the stable operation of the vehicle. The equation with the objective function of minimizing the sum of the squared utilization of the four tires is shown below.

$$
\min J=\sum_{i}^{4} \rho_{i j}^{2}
$$

The constraints of the objective function are:

$$
T_{d \max } / r \leq F_{x i j} \leq T_{l \max } / r
$$

Equation (37) is expressed as the output limit of the hub motor.

$$
\left|F_{x i j}\right| \leq \mu_{i j} F_{z i j}
$$

Equation (38) is the pavement adhesion condition limit.

According to Equations (36)-(38), the following equations can be obtained:

$$
\min _{u_{\min } \leq u \leq u_{\max }} J=u^{T} W u
$$

Among them, $W=\operatorname{diag}\left(\frac{1}{\left(\mu_{i j} F_{z i j}\right)^{2}}\right)$.

Finally, the optimal driving forces for each drive wheel $F_{x f l}, F_{x f r}, F_{x r l}, F_{x r r}$ are obtained. The optimal driving torque of each driving wheel can be obtained by Equation (40):

$$
\left\{\begin{aligned}
T_{x f l} & =F_{x f l} r \\
T_{x f r} & =F_{x f r} r \\
T_{x r l} & =F_{x r l} r \\
T_{x r r} & =F_{x r r} r
\end{aligned}\right.
$$

In this way, the optimal driving torque allocated to each driving wheel is obtained, and the additional driving torque obtained from decoupling control is input to the vehicle model together to realize the closed loop of the whole system.

\section{Simulation Analysis of Control Effects}

The simulation objects are vehicles that use PID to track vehicle speed and evenly distribute torque (marked as "No control"), vehicles based on additional yaw moment control (marked as "Yaw control"), and vehicles with acceleration slip control (marked as "Slip rate control") and decoupling optimally controlled vehicles (marked as "decoupling optimal control").

\subsection{High Adhesion Pavement Simulation Analysis}

The vehicle is simulated on a road with a road surface adhesion coefficient of 1 , accelerating from $0 \mathrm{~km} / \mathrm{h}$ along a straight line to $72 \mathrm{~km} / \mathrm{h}$ and then maintaining a constant speed.

As shown in Figure 9, under the action of no control, yaw rate control, slip rate control and decoupling optimal control, the speed all reached $72 \mathrm{~km} / \mathrm{h}$ after $8 \mathrm{~s}$ without overshooting.

As shown in Figures 10 and 11, the vehicle yaw rate and deviation (Marked as "displacement in the $Y$-axis direction") value under the four controls are very small, indicating that the four control methods make the vehicle have a good straight-line driving ability on a high-adhesion road. 


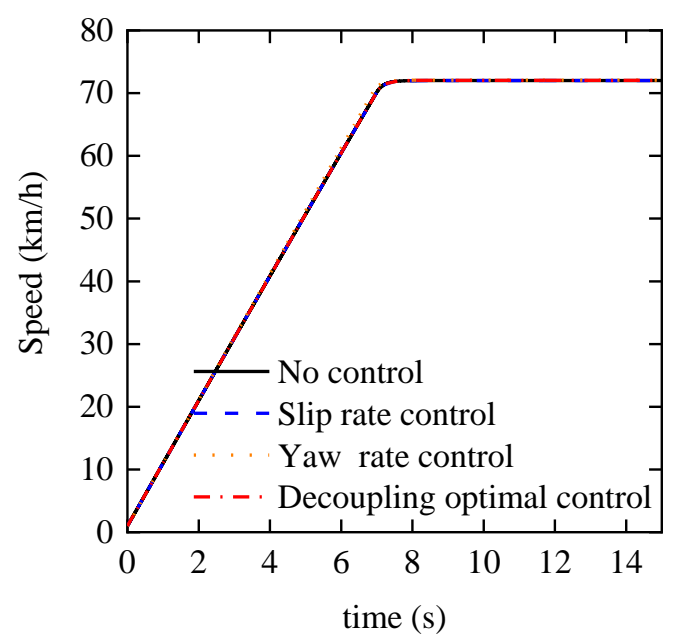

Figure 9. Vehicle speed.

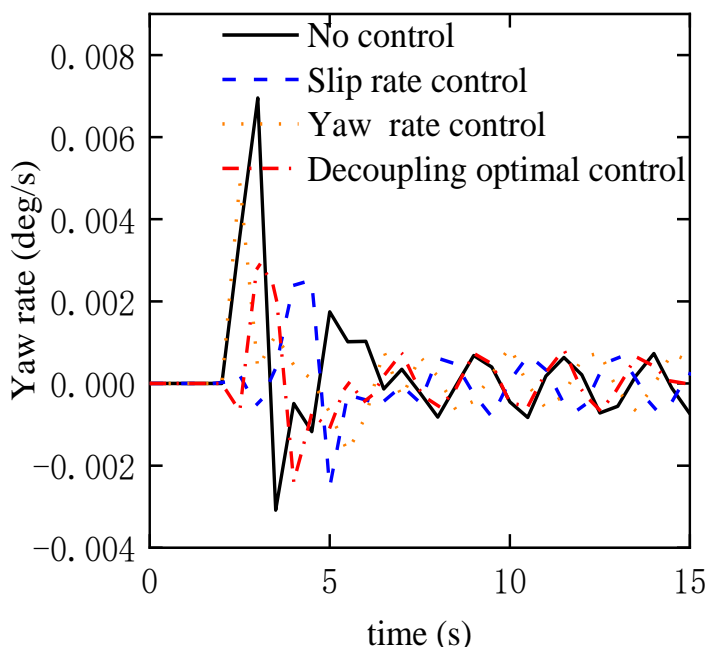

Figure 10. Yaw rate.

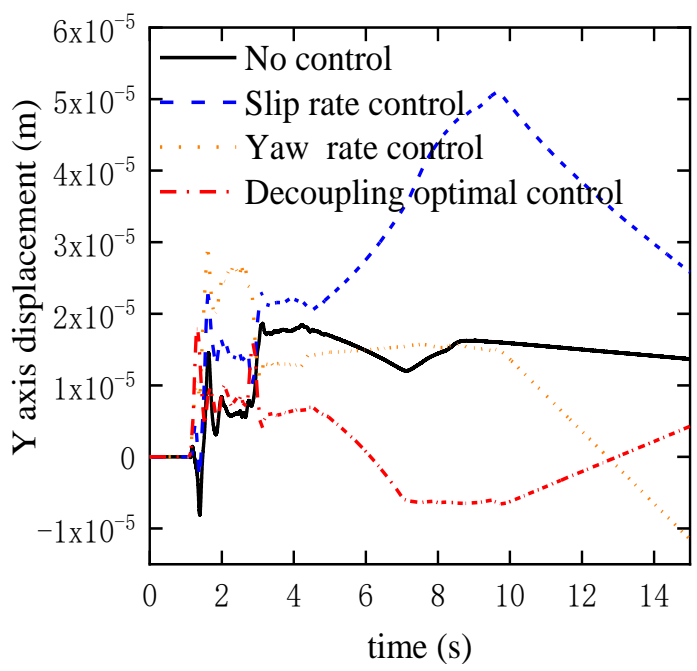

Figure 11. Displacement in the $Y$-axis direction.

As shown in Figures 12-15, in the four control modes, the front and rear wheel slip rates are maintained in a stable area without excessive slip. 


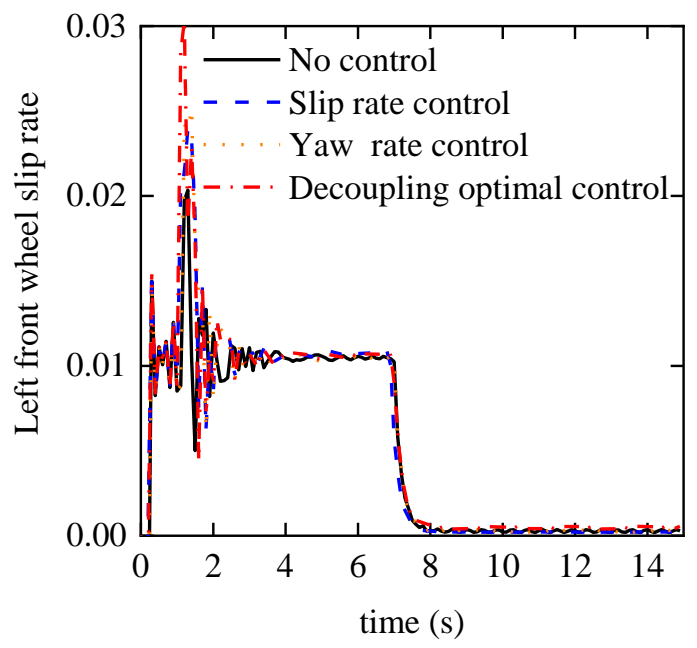

Figure 12. Left front wheel slip rate.

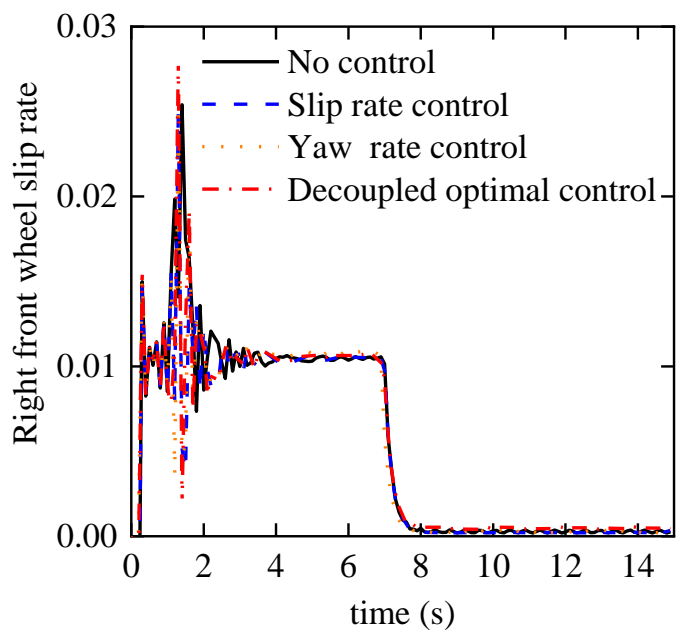

Figure 13. Right front wheel slip rate.

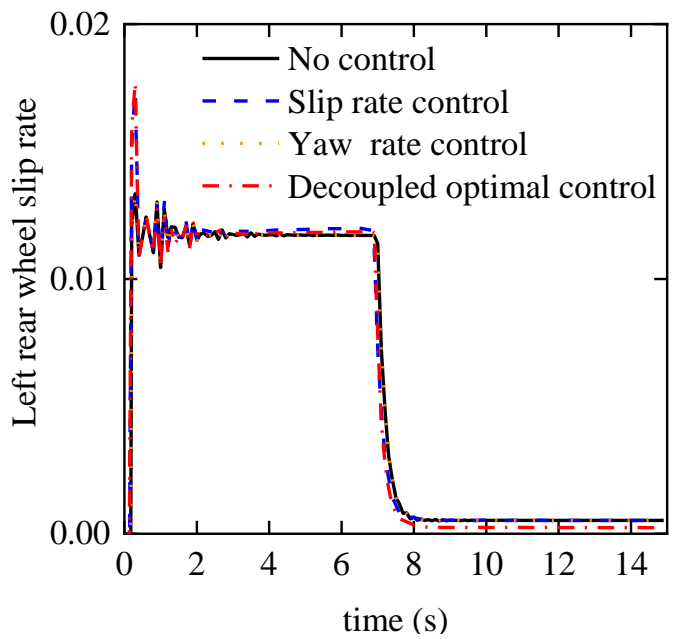

Figure 14. Left rear wheel slip rate. 


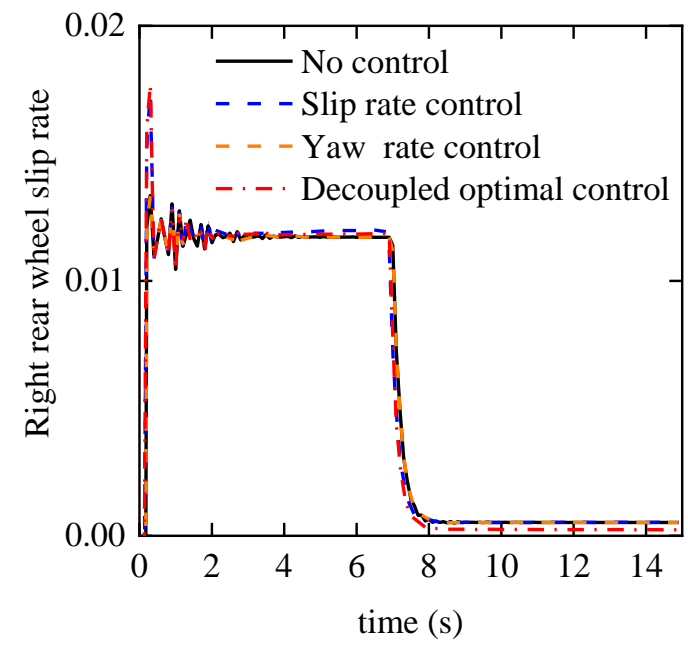

Figure 15. Right rear wheel slip rate.

This shows that all four control methods can guarantee the stability of a four-wheel independent drive electric vehicle driving in a straight line on a high adhesion road.

\subsection{Low Adhesion Pavement Simulation Analysis}

The vehicle was simulated on a road with a road surface adhesion coefficient of 0.2 , accelerating from $0 \mathrm{~km} / \mathrm{h}$ along a straight line to $72 \mathrm{~km} / \mathrm{h}$ and then maintaining a constant speed.

As shown in Figure 16, the vehicle continues to accelerate to $74 \mathrm{~km} / \mathrm{h}$ without control and then stabilizes at $72 \mathrm{~km} / \mathrm{h}$, with an overshoot of $2.8 \%$; the speed under slip rate control reaches $73 \mathrm{~km} / \mathrm{h}$ after $11 \mathrm{~s}$, with an overshoot of $1.3 \%$, after which the vehicle is driven at $72 \mathrm{~km} / \mathrm{h}$; under yaw speed control, the vehicle speed reached $73.8 \mathrm{~km} / \mathrm{h}$ after $11 \mathrm{~s}$, then stabilized at $72 \mathrm{~km} / \mathrm{h}$, and the overshoot was $2.5 \%$; under the decoupling optimal control, the vehicle speed reaches $72 \mathrm{~km} / \mathrm{h}$ in $11 \mathrm{~s}$, and then it keeps driving at a constant speed. Decoupled optimal control for vehicle speed following is more accurate and smoother than no control, slip rate control, and cross-swing angular speed control.

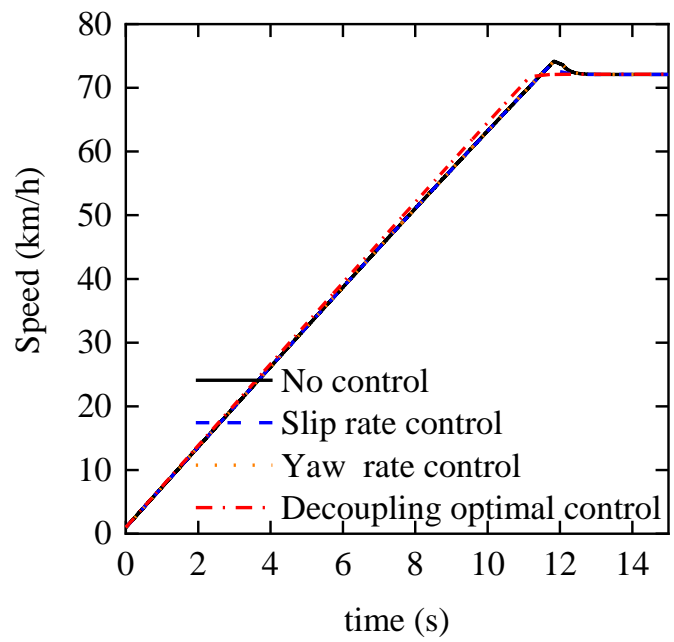

Figure 16. Vehicle speed.

As shown in Figures 17 and 18, the yaw rate and deviation of the vehicle under the four control modes are in a small range, and the vehicle has a good straight-line driving ability. 


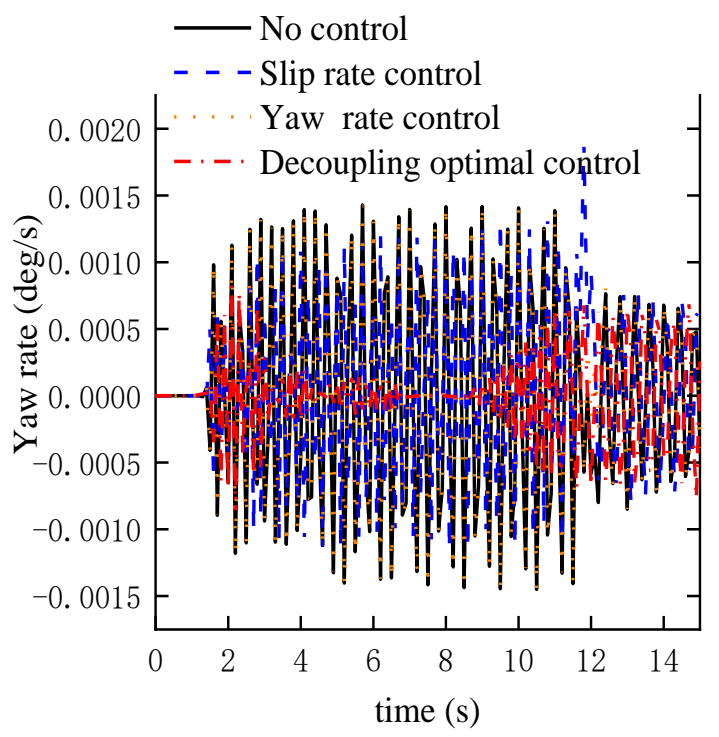

Figure 17. Yaw rate.

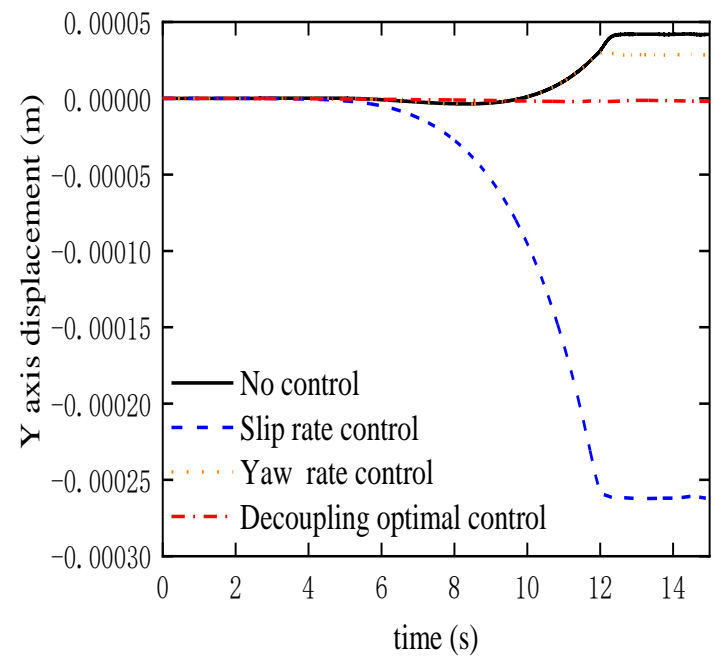

Figure 18. Displacement in the $Y$-axis direction.

However, it is clear that yaw rate control is more effective than slip rate control and that slip rate control is even less effective than no control at all, compared with the other three control methods, the decoupled optimal control significantly reduces the large fluctuation of yaw velocity during the acceleration stage.

Under the decoupling optimal control, the vehicle deviation is basically 0 , which improves the control effect by an order of magnitude compared with the other three control methods.

As shown in Figure 19, the wheels slip quickly without control and under the control of the yaw rate, and the slip rate rises rapidly. Under the action of slip rate control, although the wheel is also in a slipping state, the peak value drops by $10 \%$. Compared with the previous two control methods, it enters a safe state $0.5 \mathrm{~s}$ earlier. Under the action of decoupling optimal control, the slip rate of front and rear wheels is always maintained in the safe area. This shows that the decoupling optimal control can greatly improve the degree of wheel slip on low adhesion roads and ensure the stability of the vehicle. 

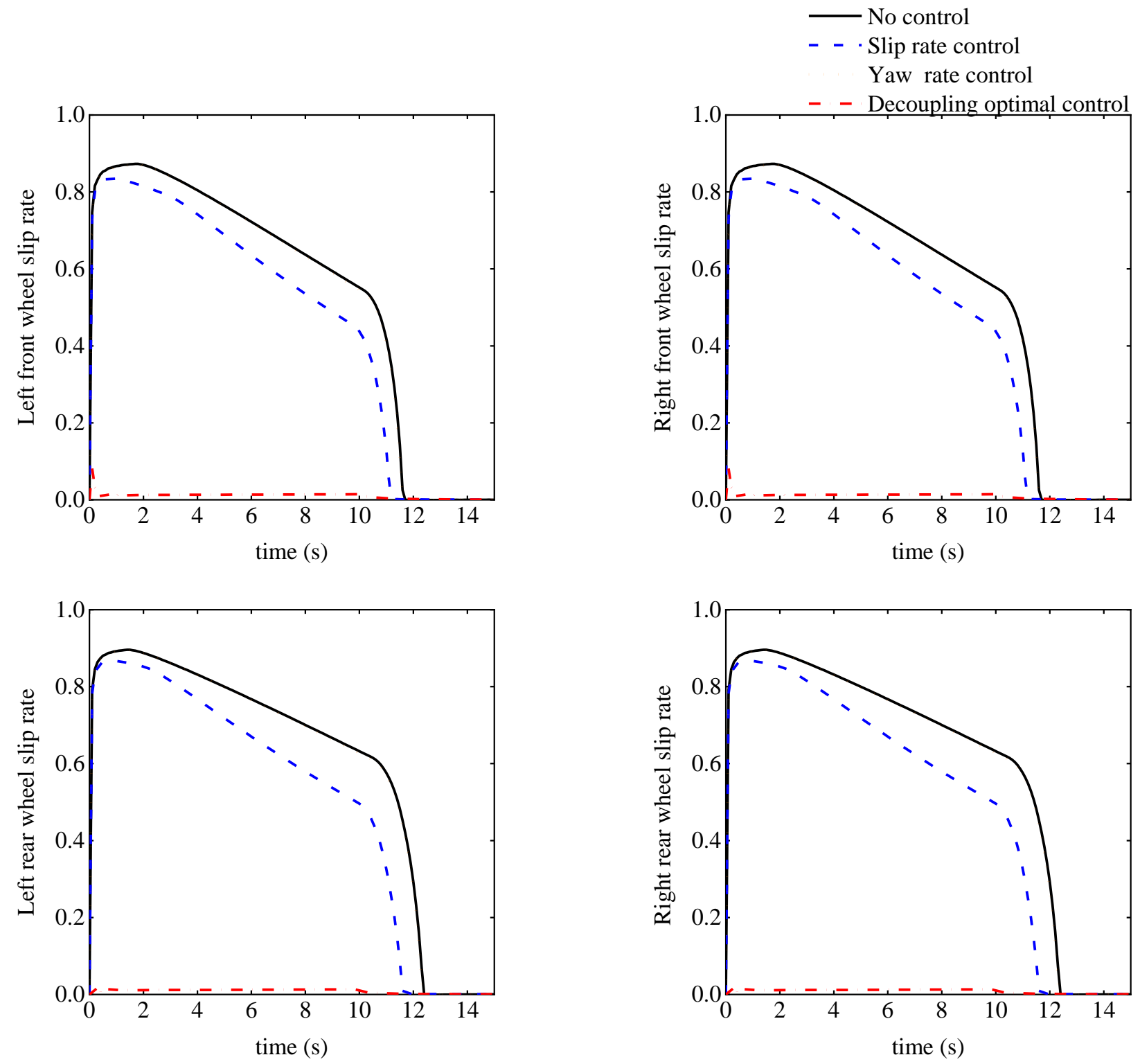

Figure 19. Slip rate.

\subsection{Simulation Analysis of Split Roads}

In order to further verify the control effect, get more obvious control the effect. The vehicle is simulated on a road with a road adhesion coefficient of 0.2 on the left and a road adhesion coefficient of 1 on the right. It accelerates in a straight line from $0 \mathrm{~km} / \mathrm{h}$ to $72 \mathrm{~km} / \mathrm{h}$, and then maintains a constant speed.

As shown in Figures 20-22, in the no controlled mode, the vehicle continues to accelerate until $72 \mathrm{~km} / \mathrm{h}$, and then the vehicle begins to skid on the road, resulting in a serious imbalance in speed. Under the control of slip rate, the vehicle accelerates to $72.8 \mathrm{~km} / \mathrm{h}$ after $12 \mathrm{~s}$, and the speed overshoots. After that, the vehicle quickly recovers to $72 \mathrm{~km} / \mathrm{h}$ and keeps a constant speed. Under the yaw speed control, the expected speed is as unstable to follow in the acceleration stage as it is without control. After accelerating to $72 \mathrm{~km} / \mathrm{h}$, the vehicle keeps constant speed. 


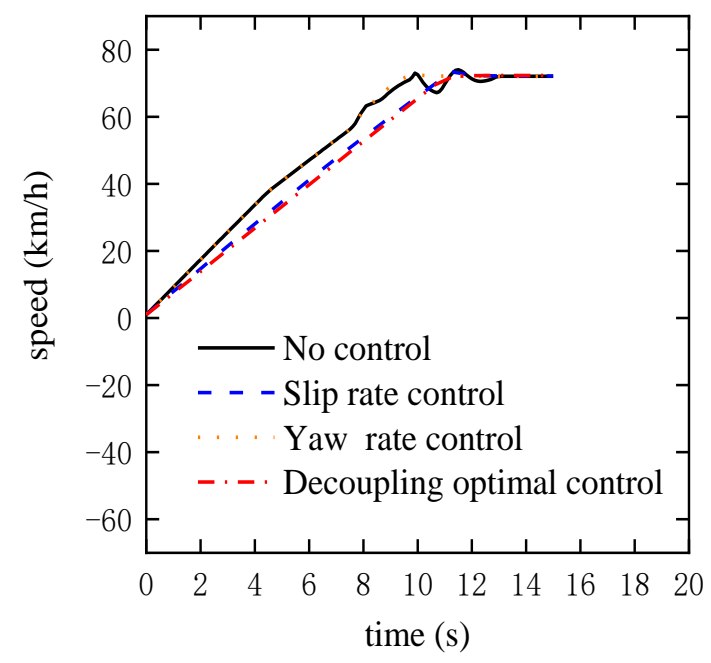

Figure 20. Vehicle speed.

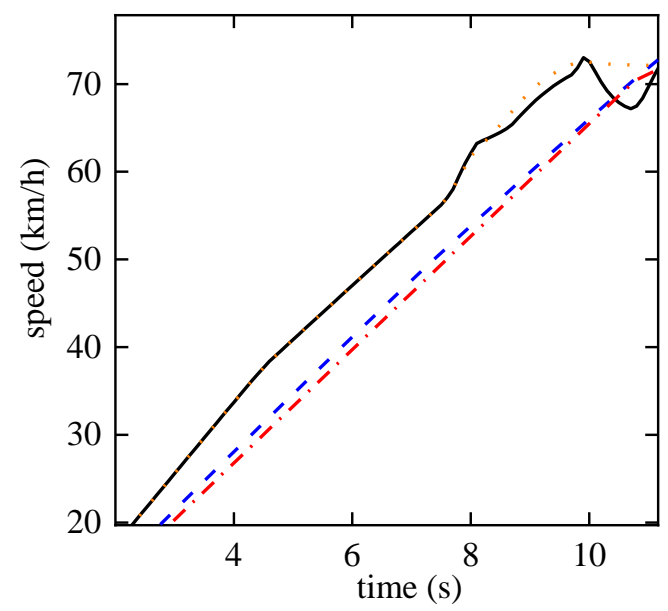

Figure 21. Enlarged view of vehicle speed.

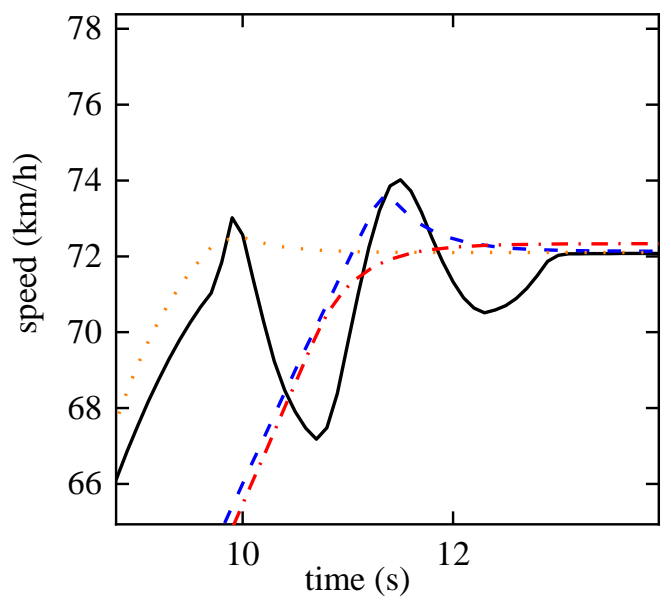

Figure 22. Enlarged view of vehicle speed.

Under the decoupling optimal control, the vehicle accelerates quickly and smoothly to $72 \mathrm{~km} / \mathrm{h}$ in $11 \mathrm{~s}$, and then maintains a constant speed.

As shown in Figures 23 and 24, the vehicle deviates greatly from the straight track without control. Under the action of slip rate control, the maximum amplitude of vehicle 
yaw rate is $18 \mathrm{deg} / \mathrm{s}$, and the maximum deviation of vehicle is $0.7 \mathrm{~m}$. Under the action of yaw rate control, the maximum amplitude of yaw rate is $2 \mathrm{deg} / \mathrm{s}$, and the maximum deviation of vehicle is $0.07 \mathrm{~m}$. Under the action of decoupling optimal control, the yaw rate of the vehicle is basically 0 , and the vehicle deviation is basically 0 . It can be seen that the decoupling optimal control has excellent effect.

- - Slip rate control

Yaw rate control

- - Decoupling optimal control
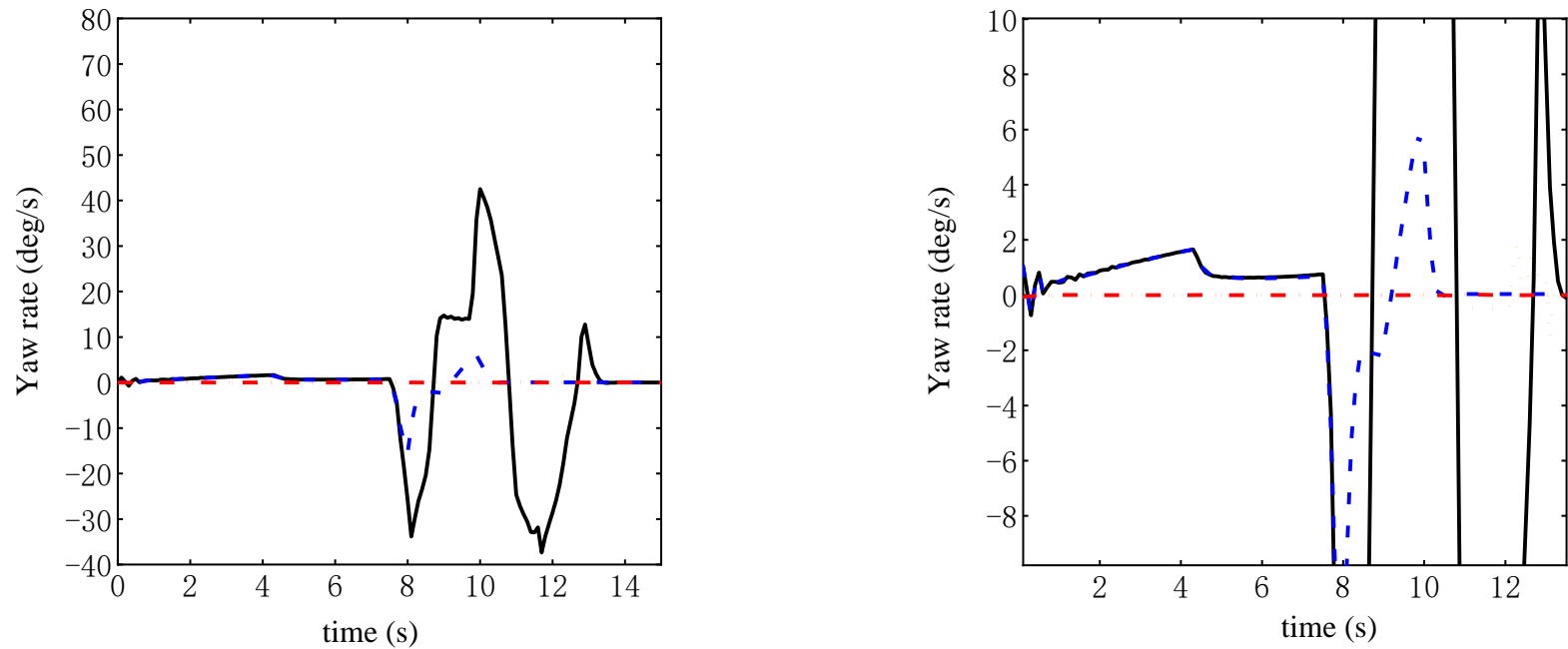

Figure 23. Vehicle speed.

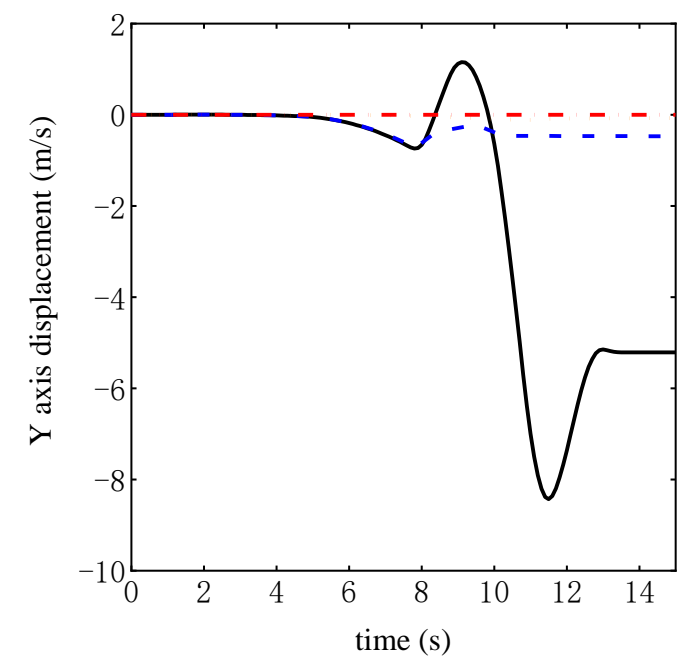

- No control

- - Slip rate control

Yaw rate control

- - Decoupling optimal control

Figure 24. Displacement in the $Y$-axis direction.

As shown in Figure 25, without control, the left wheel skids rapidly and the slip rate rises rapidly. Later, the right wheel skids rapidly and the slip rate rises rapidly due to the vehicle completely swerving to the left road surface. 

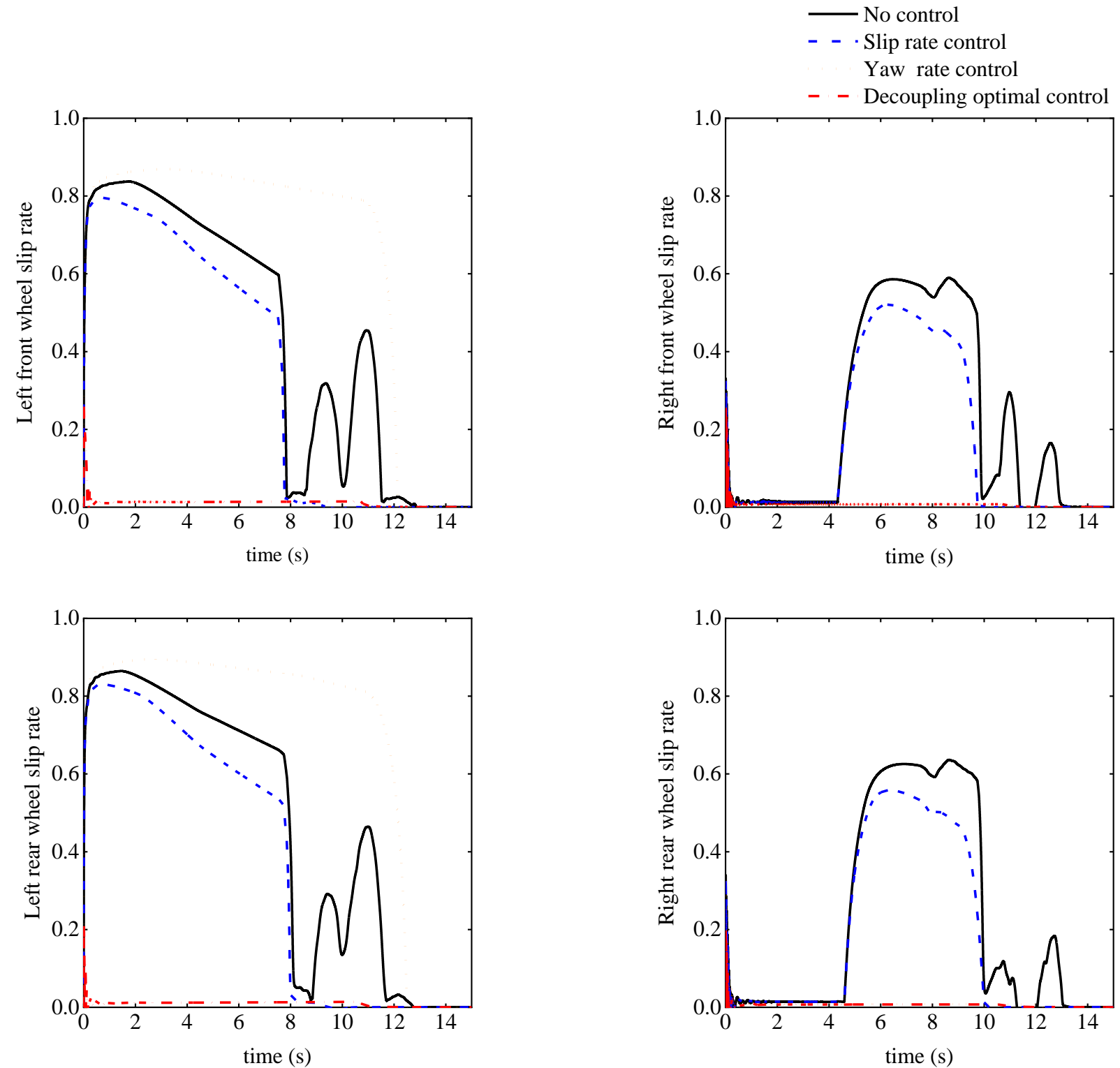

Figure 25. Slip rate.

Under the control of the slip rate, the peak slip rate of the left front and rear wheels decreased by about $5 \%$, the peak slip rate of the right front and rear wheels decreased by about $10 \%$.

Under the control of yaw rate, the slip rate of the left front and rear wheels is higher than that no control, while the slip rate of the right front and rear wheels remains in the stable zone.

Under the action of decoupling optimal control, the slip rate of left and right front and rear wheels keeps in a stable region.

The results show that the yaw rate control is weaker than the slip rate control, while the decoupling optimal control has the best effect.

\section{Conclusions}

(1) Based on the stability analysis of hub motor driven electric vehicle in straight line driving, the cause of vehicle deviation is revealed.

(2) Through the motor matching calculation, the carsim vehicle dynamics model is established, and simulation tests are carried out, which proves that the simulation 
accuracy of the model is sufficient to meet the verification requirements of the control strategy for straight-line driving conditions.

(3) The control strategy of yaw motion and slip rate was formulated. Based on model predictive control and PID control, the combined controller of yaw rate and slip rate was developed and the control decoupling was realized. Based on the sliding mode control and the least quadratic programming of the tire utilization rate, the optimal distribution of the generalized driving torque is completed. The simulation verifies the correctness of the proposed optimal control method for driving torque decoupling, and also proves that the joint control of yaw motion and slip rate can greatly improve the straight-line driving stability of the hub motor-driven electric vehicle.

\begin{abstract}
Author Contributions: Conceptualization, S.Y.; methodology, S.Y.; software, S.Y.; validation, S.Y., J.F. and B.S.; formal analysis, S.Y.; investigation, S.Y. and J.F.; resources, S.Y.; data curation, S.Y.; writingoriginal draft preparation, S.Y.; writing-review and editing, J.F.; visualization, S.Y.; supervision, S.Y.; project administration, S.Y.; funding acquisition, J.F. and B.S. All authors have read and agreed to the published version of the manuscript.

Funding: This research was funded by High-level Talents Research Start-up Fund of Shihezi University, grant number RCZK2018C07 and the National Natural Science Foundation of China, grant number 61663042.
\end{abstract}

Conflicts of Interest: The authors declare no conflict of interest.

\title{
References
}

1. Hu, J.S.; Yin, D. Electric Vehicle Traction Control: A New MTTE Methodology. IEEE 2012, 18, 23-31. [CrossRef]

2. Dadashnialehi, A.; Bab-Hadiashar, A.; Cao, Z. Intelligent Sensorless ABS for In-Wheel Electric Vehicles. IEEE Trans. Ind. Electron. 2014, 61, 1957-1969. [CrossRef]

3. Wang, J.; Wang, Q.; Jin, L. Independent wheel torque control of 4WD electric vehicle for differential drive assisted steering. Mechatronics 2011, 21, 63-76. [CrossRef]

4. Falkner, A.; Reinalter, W. Consistent vehicle model for determining the design envelope, ride comfort and component load. Veh. Syst. Dyn. 2006, 44, 468-478. [CrossRef]

5. Chen, Q.; Liao, C.; Ouyang, A. Research and development of in-wheel motor driving technology for electric vehicles. Int. J. Electr. Hybrid Veh. 2016, 8, 242. [CrossRef]

6. Fan, Y.; Zhang, L.; Cheng, M. Sensorless SVPWM-FADTC of a New Flux-Modulated Permanent-Magnet Wheel Motor Based on a Wide-Speed Sliding Mode Observer. IEEE Trans. Ind. Electron. 2015, 62, 3143-3151. [CrossRef]

7. Liu, H.; Zhang, H. An improved DTC for in-wheel BLDC motors in micro all-electric vehicles. Automatika 2016, 57, 648-659. [CrossRef]

8. Ying, F.; Li, Z.; Wei, M. The Improved Direct Torque Control of a New Self-Decelerating Permanent-Magnet In-Wheel Motor for Electric Vehicles. Vehicle Power \& Propulsion Conference. In Proceedings of the 2013 IEEE Vehicle Power and Propulsion Conference (VPPC), Beijing, China, 15-18 October 2013; IEEE: Piscataway, NJ, USA, 2013.

9. Djerioui, A.; Houari, A. Grey Wolf based control for speed ripple reduction at low speed operation of PMSM drives. ISA Trans. 2018, 74, 111-119. [CrossRef]

10. Murata, S. Innovation by in-wheel-motor drive unit. Veh. Syst. Dyn. 2012, 50, 807. [CrossRef]

11. Zhang, L. Decoupling control of roll stability of electric vehicle driven by in-wheel motor. Chin. J. Mech. Eng. 2017, 53, 94-104.

12. Bai, Z.; Lu, Y.; Li, Y. Method of Improving Lateral Stability by Using Additional Yaw Moment of Semi-Trailer. Energies 2020, 13, 6317. [CrossRef]

13. Haiying, M.; Chaopeng, L.; Fu, W.Z. Direct Yaw-Moment Control Based on Fuzzy Logic of Four Wheel Drive Vehicle under the Cross Wind. Energy Procedia 2017, 105, 2310-2316. [CrossRef]

14. Wang, Z. Vehicle Stability Enhancement through Hierarchical Control for a Four-Wheel-Independently-Actuated Electric Vehicle. Energies 2017, 10, 947. [CrossRef]

15. Wang, J.; Zheng, L.; Yan, W. Coordination Control of Differential Drive Assist Steering and Vehicle Stability Control for FourWheel-Independent-Drive EV. IEEE Trans. Veh. Technol. 2018, 67, 11453-11467. [CrossRef]

16. Kirli, A.; Chen, Y.; Okwudire, C. Torque-Vectoring-Based Backup Steering Strategy for Steer-by-Wire Autonomous Vehicles with Vehicle Stability Control. IEEE Trans. Veh. Technol. 2019, 68, 7319-7328. [CrossRef]

17. Balázs, N. Coordination of Lateral Vehicle Control Systems Using Learning-Based Strategies. Energies 2021, $14,1291$.

18. Jalali, M.; Khosravani, S.; Khajepour, A.; Chen, S.K.; Litkouhi, B. Model predictive control of vehicle stability using coordinated active steering and differential brakes. Mechatronics 2017, 48, 30-41. [CrossRef]

19. Feng, J. Research on Methods of Active Steering Control Based on Receding Horizon Control. Energies 2018, 11, 2243. [CrossRef] 
20. Mousavinejad, E.; Han, Q.L.; Yang, F.; Zhu, Y.; Vlacic, L. Integrated control of ground vehicles dynamics via advanced terminal sliding mode control. Veh. Syst. Dyn. 2017, 55, 268-294. [CrossRef]

21. Bobier-Tiu, C.G. Vehicle control synthesis using phase portraits of planar dynamics. Veh. Syst. Dyn. 2019, 57, 1318-1337. [CrossRef]

22. Huang, G. A BP-PID controller-based multi-model control system for lateral stability of distributed drive electric vehicle. J. Frankl. Inst. 2019, 356, 7290-7311. [CrossRef]

23. Shuai, Z.; Zhang, H.; Wang, J. Combined AFS and DYC Control of Four-Wheel-Independent-Drive Electric Vehicles over CAN Network with Time-Varying Delays. IEEE Trans. Veh. Technol. 2014, 63, 591-602. [CrossRef]

24. Deur, J. A model-based traction control strategy non-reliant on wheel slip information. Veh. Syst. Dyn. 2011, 49, 1245-1265. [CrossRef]

25. Yin, G. Optimal Slip Ratio Based Fuzzy Control of Acceleration Slip Regulation for Four-Wheel Independent Driving Electric Vehicles. Math. Problems Eng. 2013, 2013, 410864. [CrossRef]

26. Zhang, J.; Shi, Z.; Yang, X. Robust adaptive control for continuous wheel slip rate tracking of vehicle with state observer. Meas. Control-Lond.-Inst. Meas. Control 2020, 53, 002029402092815. [CrossRef]

27. Zhang, D. Control method of wheel slip rate based on fuzzy algorithm. J. Intell. Fuzzy Syst. 2020, 38, 7865-7874. [CrossRef]

28. Pourseif, T.; Mohajeri, M. Design of robust control for a motor in electric vehicles. IET Electr. Syst. Transp. 2020, 10, 68-74. [CrossRef]

29. Yu, Z. Automobile Theory, 5th ed.; China Machine Press: Beijing, China, 2009.

30. Tanelli, M.; Ferrara, A. Wheel slip control of road vehicles via switched second order sliding modes. Int. J. Veh. Des. 2013, 62, 231-253. [CrossRef]

31. Cairano, S.D.; Tseng, H.E.; Bernardini, D. Vehicle Yaw Stability Control by Coordinated Active Front Steering and Differential Braking in the Tire Sideslip Angles Domain. IEEE Trans. Control Syst. Technol. 2013, 21, 1236-1248. [CrossRef]

32. Ogata, K. Modern Control Engineering; Electronic Industry Press: Beijing, China, 2010.

33. Mahfouz, M.; Taiomour, A.; Ashry, M.M.; Elnashar, G. PID tuning approaches for quadrotors unmanned aerial vehicles. IOP Conf. Ser. Mater. Sci. Eng. 2021, 1172, 012040. [CrossRef]

34. Xu, M.; Wang, X.; Li, W.; Fu, H.; Wang, S. Investigation of PID Control Model Performance in Off-Road Working Vehicle Motion Stability Control System. Elektron. Elektrotech. 2017, 23, 3-9. [CrossRef]

35. Sinlapakun, V.; Assawinchaichote, W. Optimized PID controller design for electric furnace temperature systems with Nelder Mead Algorithm. In Proceedings of the 2015 12th International Conference on Electrical Engineering/Electronics, Computer, Telecommunications and Information Technology (ECTI-CON), Hua Hin, Thailand, 24-27 June 2015; IEEE: Piscataway, NJ, USA, 2015.

36. Jin, L.; Wang, Q.; Yue, W.; Song, C. Dynamics Simulation Model Based on Four-wheel Independent Drive Electric Vehicle. J. Syst. Simul. 2005, 12, 3053-3055.

37. Ossama, M.; Masato, A. Simultaneous Optimal Distribution of Lateral and Longitudinal Tire Forces for the Model Following Control. J. Dyn. Syst. Meas. Control 2004, 126, 753-763.

38. Guo, L. Cost-optimal energy management strategy for plug-in hybrid electric vehicles with variable horizon speed prediction and adaptive state-of-charge reference. Energy 2021, 232, 120933. [CrossRef]

39. Makrygiorgou, J.J.; Alexandridis, A.T. Power Electronic Control Design for Stable EV Motor and Battery Operation during a Route. Energies 2019, 12, 1990. [CrossRef]

40. Scokaert, P.O.; Mayne, D.Q. Min-max feedback model predictive control for constrained linear systems. IEEE Trans. Autom. Control 1998, 43, 1136-1142. [CrossRef]

41. Chai, R.; Savvaris, A.; Tsourdos, A.; Chai, S.; Xia, Y. Trajectory Optimization of Space Maneuver Vehicle Using a Hybrid Optimal Control Solver. IEEE Trans. Cybern. 2017, 49, 467-480. [CrossRef]

42. Zhong, G.; Kobayashi, Y.; Emaru, T. Optimal control of the dynamic stability for robotic vehicles in rough terrain. Nonlinear Dyn. 2013, 73, 981-992. [CrossRef]

43. Guo, G.; Li, P.; Hao, L.Y. A New Quadratic Spacing Policy and Adaptive Fault-Tolerant Platooning With Actuator Saturation. IEEE Trans. Intell. Transp. Syst. 2020, 99, 1-13. [CrossRef]

44. Zhang, Y.; Chen, D.; Guo, D. On exponential convergence of nonlinear gradient dynamics system with application to square root finding. Nonlinear Dyn. 2015, 79, 983-1003. [CrossRef]

45. Wang, G.; Liu, Y.; Li, S. New Integrated Vehicle Stability Control of Active Front Steering and Electronic Stability Control Considering Tire Force Reserve Capability. IEEE Trans. Veh. Technol. 2021, 70, 2181-2195. [CrossRef]

46. Yang, C. An efficient vehicle-following predictive energy management strategy for PHEV based on improved sequential quadratic programming algorithm. Energy 2021, 219, 119595. [CrossRef] 